\title{
Chapter 13 \\ Scientific Models in the Severe Acute \\ Respiratory Syndrome (SARS) Research \\ and in the Biology Curriculum
}

\author{
Alice Siu Ling Wong, Maurice M.W. Cheng, and Valerie W.Y. Yip
}

\section{New Curriculum Goals of Hong Kong Science Education}

In response to the rapid advancement of science and technology, science education in Hong Kong has seen a shift from predominantly content-focused goals to a wider goal of promoting scientific literacy. Appreciation of nature of science (NOS) is often regarded as an important component for scientific literacy.

The importance of promoting students' understanding of nature of science (NOS) has been explicitly spelt out in the Curriculum and Assessment Guides of the science subjects in Hong Kong (CDC-HKEAA, 2007). Such goals are in line with the science curricula in many other countries (e.g., American Association for the Advancement of Science, 1993; Council of Ministers of Education, 1997; Millar \& Osborne, 1998). Earlier studies reported the disappointing findings that both students and science teachers have inadequate understanding of NOS (Lederman, 1992); however, there is encouraging empirical evidence that can inform initiatives to improve NOS understandings. Explicit and reflective approaches in teaching NOS can support learner development of sophisticated NOS ideas (Abd-El-Khalick \& Lederman, 2000; Khishfe \& Abd-El-Khalick, 2002). The critical review of Abd-El-Khalick and Lederman suggested that "approaches that utilize elements from history and philosophy of science and/or direct instruction on NOS are more effective in achieving that end than approaches that utilize science process-skills instruction or non-reflective inquiry-based activities" (p. 694).

Being cognizant of the challenges about teachers' general inadequate understanding of NOS and pedagogical skills in teaching NOS in Hong Kong, our preservice and in-service science teacher education programs were restructured to align with the direction of the curriculum reform. Since the early 2000s, we have

\footnotetext{
A.S.L. Wong $(\bowtie) \cdot$ M.M.W. Cheng • V.W.Y. Yip

Faculty of Education, The University of Hong Kong, Pokfulam Road, Hong Kong SAR, China

e-mail: aslwong@hku.hk; mwcheng@hku.hk; valyip@hku.hk
} 
made use of science stories, such as the discovery of penicillin, the development of cowpox, Newton's proposition of law of universal gravitation, and the treatment of stomach ulcers (Tao, 2002) as a medium through which NOS could be introduced. However, due to the lack of both understanding of NOS and experience in learning and teaching NOS, many teachers who have not formerly participated in our teacher education program only saw these stories as a good means of arousing students' interest without having noticed the intended learning outcomes of NOS understandings. Such a situation was reflected in the comment made by a junior science teacher who had been telling the interesting science stories to his students. He came to realize his oversight of not having made good use of the stories for teaching NOS after he had attended our NOS in-service education workshop:

I found the story on stomach ulcers very interesting.... Marshall tested his hypothesis by trialing out himself.... Students all enjoyed the story... I only realized now that there are deeper meanings behind the story and other important learning outcomes to be achieved through it and other stories.

There were further inadequacies of these relatively old stories. Teachers and students expressed the view that though these stories aroused their interests, they happened quite a while ago. Those who did not have the historical and cultural backgrounds of the scientific discoveries and inventions would fail to develop an indepth understanding of, and hence appreciate, the thought processes of the scientists related to what they encountered at their time.

Bell, Blari, Crawford, and Lederman (2003) and Schwartz, Lederman, and Crawford (2004) investigated the effectiveness of promoting NOS understanding among high school students and preservice teachers by providing the authentic research experience of working with practicing scientists. The results showed that better understanding of NOS does not necessarily result from doing science per se (Bell et al., 2003). There also needs to be frequent opportunities for reflection on NOS in the context of that authentic scientific research experience through journal writing and seminars (Schwartz et al., 2004). In their comparison of the epistemic beliefs of chemistry students and research chemists, Samarapungavan, Westby, and Bodner (2006) came to the broadly similar conclusion that apprenticeship experiences are no automatic guarantee of epistemic development in students. They suggested that engaging students and expert researchers in conversation and reflection on epistemic issues related to research work will have a greater chance of success. While apprenticeship or internship experiences offer enormous potential for enhancing NOS understanding, they created major logistic problemsespecially in East Asian classrooms, where class size is routinely about 40. Our response has been to present students with insights into authentic scientific practice through the development of a case study of contemporary scientific practice that shows the importance of developing models to understand the phenomenaprocedure essential in the understanding of NOS.

In the summer of 2003 when the crisis due to the severe acute respiratory syndrome (SARS) in Hong Kong was coming to an end, we saw a golden opportunity to turn the crisis into a set of instructional resources which aimed to address the issues raised above. 
The SARS incident was a unique experience through which everyone in Hong Kong had lived and the memories of which would stay for years to come. At the beginning of the outbreak, the causative agent was not known, the pattern of spread was not identified, mortality was soaring, yet an effective treatment regimen was uncertain. It attracted the attention of the whole world as scientists worked indefatigably to understand the biology of the disease, develop new diagnostic tests, and design new treatments. Extensive media coverage kept people up to date on the latest development of scientific knowledge generated from the scientific inquiry about the disease.

The details on how we made use of the news reports and documentaries on SARS, together with episodes from the scientists' interviews - to develop a set of instructional materials and to explicitly teach a wide range of prominent features of NOS identified in the authentic scientific research — can be found in Wong, Hodson, Kwan, and Yung (2008). Since January 2005, we have been using the SARS story in developing NOS understanding among hundreds of preservice and in-service science teachers. The contextual approach which situated the learning of NOS in the authentic scientific research during the SARS epidemic was found to be particularly successful in promoting teachers' understanding of NOS in terms of (1) the realization of inseparable links between science and the social, cultural, and political environment; (2) deeper understanding of how science and technology impact on each other; and (3) a richer appreciation of the processes of authentic scientific inquiry and the humanistic character of scientists (Wong, Kwan, Hodson, \& Yung, 2009). We have also recently reported some exemplary classroom practice translating teachers' own effective learning involving these NOS aspects in their science lessons (Wong, Wan, \& Cheng, 2011). However, we are mindful not to be complacent with the learning of the three areas of NOS aspects as we noted less sophisticated discussion on the role and nature of scientific models and modeling in classroom practice (Cheng, Wong, \& Yung, 2007), let alone the discussion of multiple levels of representations in science.

In this chapter, our discussion is centered on the role of models and the prominent activity of model building as shown in authentic scientific inquiries during the SARS epidemic. By following more subsequent research findings and reports related to SARS, we have recently enriched our teacher education materials to strengthen the discussion of these important aspects of NOS. We then compare and contrast the nature of models and modeling as reflected in authentic scientific practice and that appear in the Biology Curriculum and Assessment Guide (CDC-HKEAA, 2007). In Hong Kong, biology is arguably the science subject that has placed greatest attention to NOS. Many local biology teachers also believe that understanding of NOS will be assessed in the public examination for the reformed curriculum (Kwan, 2011).

\section{Models and Modeling in Research on SARS}

This section elaborates the series of events that occurred in four key scientific inquiries during the SARS epidemic, namely, (1) the identification of the transmission mode of SARS and (2) the hunt for the causative agent of SARS, (3) the search for the 
natural host of the SARS-related coronavirus, and (4) the modeling of the mysterious transmission rate and infection pattern in the tragic outbreak at Amoy Gardens. For each scientific inquiry, we highlight the important roles and characteristics of models, modeling, and the multiple levels of representations of science.

\section{New Infectious Disease: Identification of Transmission Mode of SARS}

The first scientific inquiry during the beginning of the SARS crisis was prompted by the urgent societal demand for the understanding of the transmission mode of SARS.

Starting from November 2002, there had been rumors that a mysterious atypical respiratory illness (later known as SARS) had occurred in Guangzhou, southern China. Around mid-February 2003, Dr. Liu from Guangzhou, who was infected with SARS virus but not knowing its morbidity, visited Hong Kong. He stayed at the Metropole Hotel, from where SARS started to creep into the Hong Kong community. A number of residents living in the hotel were infected. Most of them left Hong Kong by air to other countries and quickly spread the disease to the rest of the world without anyone or even the World Health Organization (WHO) noticing. By 4 March 2003, a Hong Kong young man visited a friend staying on the same floor at the Metropole Hotel as Dr. Liu got infected. He was admitted to the Prince of Wales Hospital. He then became the index patient of the outbreak in this hospital where over 100 medical doctors and other healthcare workers got infected within days and the following weeks.

By 15 March 2003, WHO was then aware of the severity of the disease and formally named the disease as SARS. A list of symptoms and a set of preventive measures and guidelines were disseminated to hospitals all over the world. It started with symptoms including high fever, headache, and dry cough. Most cases developed into pneumonia. Cases with serious buildup of fluid and inflammation of the lungs were admitted into hospitals.

The Hong Kong government started to disseminate guidelines and advice related to the likely transmission means of SARS disease through various media. A number of preventive measures were quickly put in place in Hong Kong, including cleaning of lift buttons every $2 \mathrm{~h}$ with diluted bleach and taking body temperature before going to school and work.

\section{Models/Modeling/Multiple Levels of Representations Related to Identification of Transmission of SARS}

As SARS spread in Hong Kong and in different parts of the world, epidemiologists (who study transmission and control of diseases) would have to review and screen a 


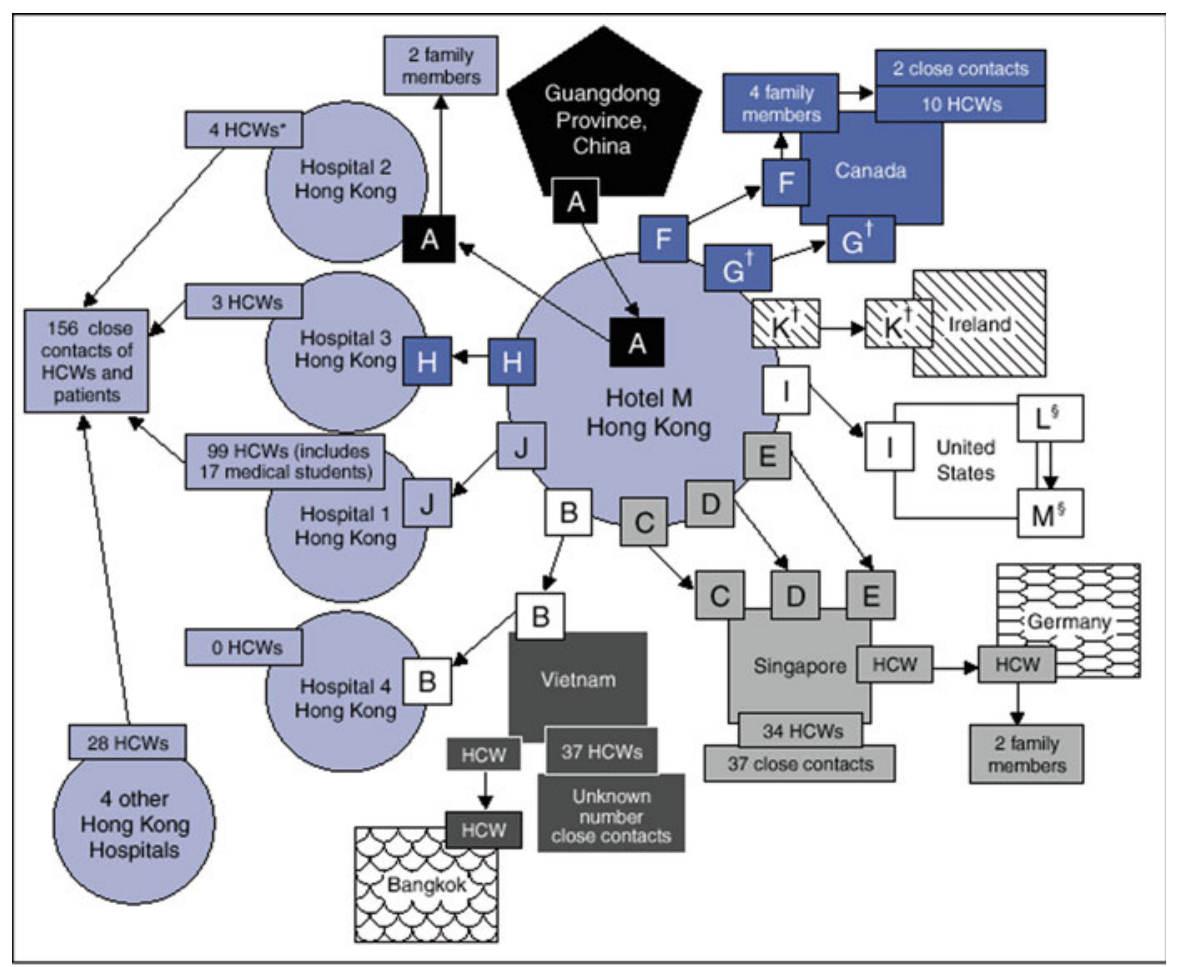

¿ Health-care workers.

${ }_{5}^{t}$ All guests except G and K stayed on the gth floor of the hotel. Guest G stayed on the 14th floor, and Guest K stayed on the 11 th floor.

${ }^{5}$ Guests L and M (spouses) were not at Hotel M during the same time as index Guest A but were at the hotel during the same times as Guests G, H, and I, who were ill during this period.

Fig. 13.1 Chains of transmission showing how SARS spread from the Metropole Hotel to other parts of Hong Kong and the world as of late March in 2003 (Reproduced with permission from Centers for Disease Control and Prevention, Altanta 2003, p. 243)

massive amount of information, for example, the profile of SARS patients, clusters where people got infected, and infectivity of the disease. They could then model the chain of infection, patterns of spread, and the speed of transmission and hence pinpointing Dr. Liu and Metropole Hotel as the origin of the initial cases. As shown in Fig. 13.1, such a systematically organized diagrammatic representation of the pattern and sequence of infection at the macro level ${ }^{1}$ (Fig. 13.1) led to their further proposal of a model at the micro level which suggested that the key means of transmission of SARS disease was through close contact with respiratory droplets containing the SARS viruses (e.g., through aerosols from coughing leaving viruses on public facilities or surroundings like lift buttons, door handles).

\footnotetext{
${ }^{1}$ We adopt the labels proposed by Gilbert and Treagust (2009) for different levels of representations (i.e., the macro, the submicro, and the symbolic).
} 
With the most probable transmission mode and spreading rate of SARS virus (at the micro level), a set of preventive measures for the public and healthcare personnel working in the hospitals could then be recommended. The set of preventive measures stand as important products which result from the predictive power of a scientific model (in this case, the mode of transmission of SARS) deduced by modeling of the available data.

\section{Hunt for Causative Agent of SARS}

The second important scientific inquiry was the hunt for the causative agent. With the knowledge of the causative agent, diagnosis of SARS and a possible cure could be found.

On 18 March 2003, the virologists at the Chinese University of Hong Kong first announced that they had found evidence that the SARS virus was a member of the paramyxovirus family, a human metapneumovirus. Immediately afterward, scientists from Germany, Singapore, and Canada also announced they had found evidence of paramyxovirus in the samples collected from SARS patients. The announcement by the first research group and the immediate subsequent confirmation by the other laboratories came as exciting news for the world as it gave hope of prompt actions to cure the disease.

In less than 3 days' time, the University of Hong Kong found evidence suggesting that coronavirus is the primary cause of SARS. A team of microbiologists had isolated the virus from a SARS patient. The halo of dots surrounding the virus observed through an electron microscope was strongly suggestive of coronavirus, and it was further confirmed by the genetic analysis that showed fragments of genetic materials that was distinctive to the coronavirus family. After their announcement, scientists from Rotterdam and CDC in Atlanta also quickly announced that they had also found evidence in favor of coronavirus as the causative agent of SARS.

Subsequent stronger evidence was further provided by scientists in Netherlands showing that the SARS coronavirus fulfilled Koch's postulates by the experiments in which monkeys infected with the virus developed the same symptoms as human SARS victims. On 12 April 2003, the first genomic sequence of the SARS coronavirus was mapped just 20 days after its discovery. Never in the history of science had the genome of a new disease-causing agent been sequenced in such a short time.

\section{Models/Modeling/Multiple Levels of Representations Related to Hunt for Causative Agent of SARS}

Scientists had a tendency to accept newly proposed models or explanations if they tied in with their expectation. It was the case in the identification of the causative 
agent for SARS when they could also find the same type of virus in most samples collected from the SARS patients.

It is commonplace that scientists' observations are influenced by their knowledge and the theoretical framework they employ, that is, their observations may be affected by what they expect to see based on some initial scientific models in their mind. Coronavirus is well known to cause mild common cold, and hence many scientists did not make any linkage to it as the causative agent of SARS, not until it was later believed to be mutated into a more severe form of pneumonia. Development of scientific models is a prominent and important activity in the scientific community in the pursuit of understanding and appreciation of the neatness and beauty of the natural phenomena. Scientific models with stronger supportive evidence and greater explanatory and predictive power possess higher status. The experiment based on Koch's postulates made coronavirus the more likely candidate as the causative agent.

As biology has advanced into the molecular regime, a disease can now be understood comprehensively at different levels of representations. Using the case of SARS as an example, it could be understood at the macro level in terms of the symptoms expressed by the host of the disease. Indeed, the submicro level of representation of a disease only became available after the invention of microscope. The form of representation also evolved from hand-drawn figures in the past to the current highresolution digital photos. At the submicro level, the SARS coronavirus would show a typical crown-like halo of spikes on the outer shell of the virus under an electron microscope. At the molecular level, the whole genome can now be obtained and often expressed in symbolic representation.

\section{Search for Natural Host of SARS-Like Coronaviruses}

Finding the natural reservoir of SARS-like coronaviruses is important for preventing and controlling future outbreaks of SARS. This search had begun ever since the human SARS coronavirus was identified as the causative agent of SARS in mid-April 2003. Such a search was performed by genetic analysis of the viral samples collected from SARS patients and other possible hosts.

Evidence showed that the early SARS patients in southern China were mostly chefs and restaurant workers who handle wild animals and serve exotic food like civet cats. It prompted researchers-from the University of Hong Kong and Shenzhen Center for Disease Control and Prevention-to collect samples from animals and animal traders for testing if there were SARS-like coronaviruses. In May 2003, the researchers found that civet cats carried a coronavirus that was $99.8 \%$ genetically identical to the human SARS coronavirus. They also found some animal traders who were involved in slaughtering the animals had antibodies of the virus carried by civet cats. These data indicated that the virus was passing between animals and humans. Yet without concrete data, they consciously commented that civet cats might have been infected from yet another unknown animal source. 
Nevertheless, as this was a concern for global health, the researchers immediately reported the data to the officers in Guangzhou. The provincial authorities across China banned the sale of civet cats and wild animal species and tightened up regulations on animal trade from late May 2003. This directly affected the livelihood of those who sold wild animals. The findings had also impacted on the habit of eating wild animals in China. People are now less keen on eating wild animals as before. These events represent an example where science impacts on political decision, social, and cultural practices. Subsequent studies reported in 2004 and early 2005 revealed no widespread infection in wild or farmed civets. Such findings indicated that civet cats were more likely an intermediate host which got infected in the markets where they were caged in close proximity with other animals carrying the virus.

A research team then turned their attention to bats which had been found to be reservoir hosts of several types of viruses. The increasing presence of bats and bat products in food and traditional medicine markets in southern China and elsewhere in Asia was also a contextual factor which pointed to bats as their next target ( $\mathrm{Li}$ et al., 2005). They did found SARS-like coronaviruses when they started surveying different species of bats in the search for the natural reservoir of SARS coronavirus. They then generated the genomic sequences of the viral samples from bats carrying the SARS-like viruses, infected civet cats, and infected human beings to study the evolutionary history of the SARS-like coronavirus. In October 2005, the scientists reported the phylogenetic trees (or evolutionary trees) constructed after a series of tedious comparison of the genomic patterns and logical reasoning in the deduction of the order of changes that happened to the genomic sequence of the strains during the evolution of the viral strains. Figure 13.2 shows a simplified form (for ease of illustration) of a typical phylogenetic tree, essentially scientific model, constructed by the scientists. The tree indicated bats as the likely natural host of the SARS-like coronaviruses. This finding would be welcomed by people who would benefit from the understanding and knowledge of the natural host and the interaction between the host, intermediate host, and human beings. Prevention of future outbreak thus becomes more feasible. Of course employers and employees of the restaurants serving exotic animals would not be too pleased to know that the ban of sale of civet cats (political decision) which had affected their livelihood was based on less than robust scientific evidence.

\section{Models/Modeling/Multiple Levels of Representations Related to Search for Natural Host of the SARS-Like Coronavirus}

Similar to the hunt of the causative agent of SARS coronavirus, it is essential that the modeling and models (evolutionary trees) generated in the identification of the natural reservoir should be consistent with the observations and guided by logical reasoning governed by some known criteria, for example, the variation of the genomic sequence from one stage to the next will not be drastically different from the previous one to the 


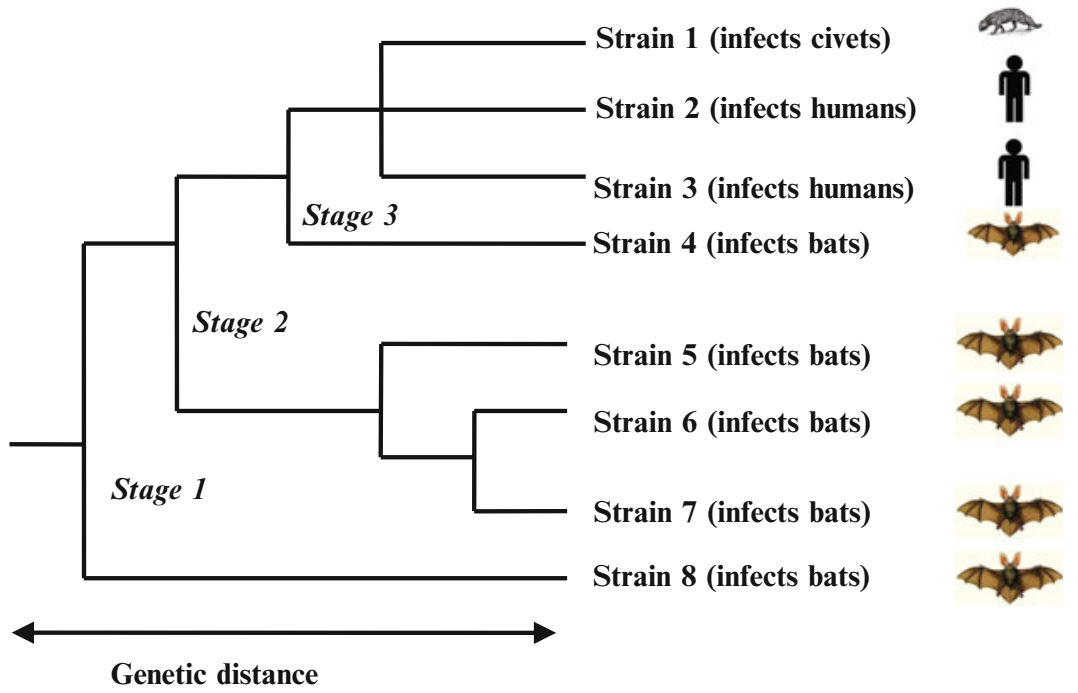

Fig. 13.2 A phylogenetic tree showing the evolutionary pattern of the bat SARS-like coronavirus mutated into human SARS coronavirus strains 2 and 3

next sequence. In the search of the natural host of the SARS-like coronaviruses, phylogenetic trees or evolutionary diagrams should illustrate the proximity of the viruses from bats, civets, and humans in terms of the genetic distance (see Fig. 13.2). As shown in the left of the phylogenetic tree, all these viruses share a common ancestral strain found in bats. Given the time for mutation, two strains were formed (stage $1^{2}$ ). One strain shares similar genetic composition as the ancestor (strain 8), whereas the other evolved (stage 2) to form several new species that only infect bats (strains 5-7), and another evolved to form viruses infects bats, civets, and humans (strains 1-4). The reason why the coronavirus found in civets (strain 1) are so similar to the human strains (strains 2 and 3) is that they share the same recent ancestor evolved in stage 3. Moreover, viral strain 4 (infecting bats) and strains 1-3 are placed at the same level in the diagram, indicating the high possibility of the bat virus spreading to humans either by direct contact or through civets (or the animals) sold in the markets.

A phylogenetic tree, essentially a scientific model, is constructed based on careful comparison of genomic sequence of each viral strain, that is, thorough understanding of the molecular level (or submicro level) of the different viral strains obtained from the genomic sequence of each viral strain. Scientists frequently have to communicate through representations of a part of or the whole genome to develop the evolutionary diagram which is at the symbolic level. In other words, modeling and models in constructing a phylogenetic tree also require knowing how to represent and communicate the models at the symbolic level.

\footnotetext{
${ }^{2}$ The stages written here are for illustration purpose. There should not be any labels such as stages in a typical phylogenetic tree. Similarly, the arrow for genetic distance is optional in this diagram.
} 


\section{Tragic Outbreak at Amoy Gardens}

Amoy Gardens, a residential complex comprising 19 blocks, was found to have an alarming number of cases of infection. New infected cases rose from 7 to 185 within 4 days. By 31 March 2003, most of the new cases in Hong Kong were from Amoy Gardens and most of the cases from Amoy Gardens were from Block E. Among them, most were residents from Flat 7 and Flat 8 (see Fig. 13.3).

On 31 March 2003, the Department of Health imposed quarantine on Block E of Amoy Gardens - an unprecedented order from the Hong Kong government to move all residents of Block $\mathrm{E}$ to isolation camps. This quarantine allowed a thorough investigation (by a cross-disciplinary investigation team consisting of epidemiologists, engineers, virologists, and other experts) to find clues to the causes of the devastating outbreak and the puzzling infection pattern.

The quarantine order sped up the scientific inquiry by the investigation team for the possible causes of the infection happened in Amoy Gardens, especially the widespread infection in Block E. From early to mid-April, scientists obtained the following crucial findings through epidemiological and environmental investigations as documented in their report to the government on 17 April 2003 (Department of Health, Government of Hong Kong Special Administration Region, 2003):

- The index patient (first case of the Amoy Gardens outbreak) visited his relatives on 14 and 19 March 2003 in a flat of Block E in mid-March around the time he developed SARS. He was having diarrhea at that time and he used the toilet there.

- Scientists collected every possible type of sample including the air, the water stored in the tank for the use of residents of Block E, the sewage system, as well as cats, dogs, rats, and cockroaches in and around Block E. They quickly identified the presence of SARS coronavirus in rats, cockroaches around the residential area, and the sewage from the drainage system of the building.

- Many Amoy Gardens residents reported foul smell in their bathrooms which suggested that the U-shaped water trap (U-traps) of the floor drainage system might not be filled with water to perform the proper function of preventing foul smell and insects from entering the bathrooms. (As the toilets, the basins, and the bathtubs were frequently used, their U-traps should be charged with water and should have been functioning properly. However, most households had the habit of cleaning the bathroom floor by mopping instead of flushing it with water, and the U-traps of the floor drains were likely to be dry and not functioning properly.)

- The pattern of vertical spread of the infection (most of the infected residents lived in Flat 7 and Flat 8, with more cases on higher floors) suggested a close connection to the sewage system that is connected to the same drainage system.

- However, the drainage system alone could not explain the high infection rate of the higher floors. It was then postulated that habit of the use of exhaust fan during the use of the bathroom might explain such a pattern.

- [Later epidemiological data revealed that "those who had used their exhaust fans while taking a shower had a five times greater chance of getting SARS" (Abraham, 2004, p. 75).] 

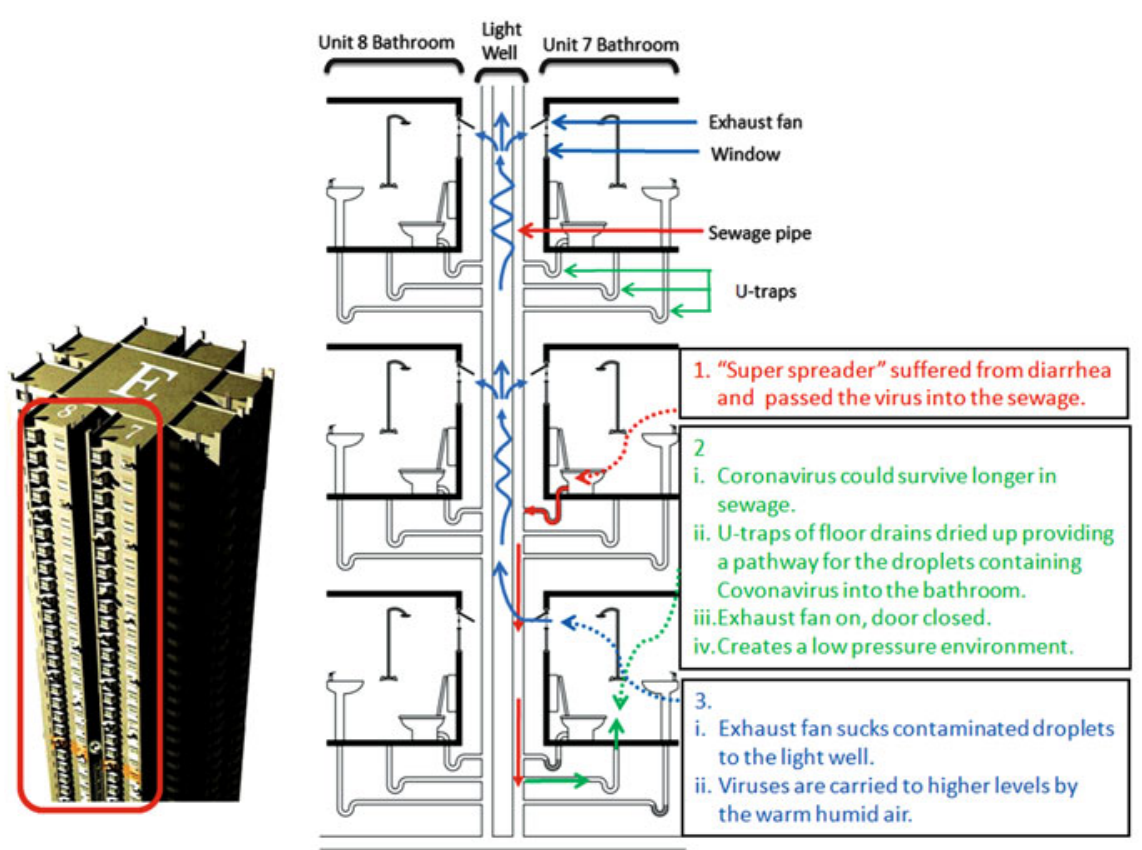

Fig. 13.3 Diagrammatic representation of the model which explains the peculiar infection pattern and its fast transmission rate

The newly constructed model was widely reported in different media in Hong Kong and quickly drew people's attention to an overlooked hygienic measure of proper use of U-traps in the bathrooms.

WHO initially had reservation about the proposed transmission model as the explanation of the infection rate and pattern. The model proposed by the Hong Kong scientists was only accepted by the scientists of the WHO after they had conducted an independent investigation in Amoy Gardens during the visit to Hong Kong in late April. Better understanding of the building structure, the drainage systems, and the overpacked conditions of the neighboring flats enabled them to appreciate the investigation and conclusions by the Hong Kong investigation team.

\section{Models/Modeling/Multiple Levels of Representations Related to Tragic Outbreak in Amoy Gardens}

Development of scientific models is sometimes prompted by an urgent demand by society in tackling societal and global problems instead of just being driven by curiosity or competition among scientists in their understanding certain aspects of 
the natural world. Such a demand together with unreserved funding and resources from the government could hugely speed up the whole process.

The diagrammatic representation of the model proposed by the cross-disciplinary investigation team is given in Fig. 13.3. It depicts how the unfortunate outbreak in Amoy Gardens occurred due to a combination of a series of rare events: (1) The index patient who turned out to be a superspreader had introduced considerable amount of SARS coronavirus into the sewage drainage system which was shared by residents of Flat 7 and Flat 8. (2) The U-traps of the floor drains in the bathrooms of some flats were dried up and opened a pathway for small droplets containing coronavirus into the bathrooms. (3) The exhaust fan which was too powerful for a small bathroom typical in Hong Kong then sucked the contaminated droplets to the light well. ${ }^{3}$ (4) The viruses were carried to floors higher up by the warm humid air (the socalled chimney effect) through open windows.

Modeling is a typical process in scientific research that offers an explanation to observations. It is noteworthy that parts of the models could be grounded on available empirical data but some could only be derived based on logical deduction when the availability or accessibility of the data is limited.

Although science in the making is more likely to be subject to changes, the government decided the risk of slow action was not affordable. Even if the model might not be fully correct, preventive actions based on the newly constructed model should cause no harm. It is not uncommon to rely on the most recent scientific models to make decision. It is always a balance of pros and cons of the different consequences that would be incurred if a model is adopted or not and if it is valid or not.

Good understanding of the contextual and environmental conditions as well as the social practice is crucial in the identification of the bits and pieces for formulating the explanatory model. The combined effort from the local team and the WHO team could capitalize on the best of both teams in terms of their developmental and confirmatory roles in the proposed model. The Hong Kong team's familiarity of local practices (e.g., habit of cleaning floor by mopping instead of flushing it with water might result in dried-up U-traps) and the evaluation of the model by the WHO team as an independent reviewer gave weight to the proposed model.

\section{Prominent Roles and Functions of Models and Modeling in Authentic Research}

From the above four episodes, we could identify some prominent roles or functions served by models. First, some models serve to organize some complex data in a systematic manner so that patterns, trends, or relationships could be more easily

\footnotetext{
${ }^{3}$ A light well is an architectural design of an open area or vertical shaft in a building bringing natural light to the lower floors. In Hong Kong, the long and vertical space between neighboring flats from the bottom to the top floors is typically referred to as a light well. The long and narrow space (almost like a long chimney) between Flats 7 and 8 of Block E (see Fig. 13.3) is a typical example in a crowded residential complex.
} 
identified, for example, the diagrammatic representation in Fig. 13.1. Second, some models are constructed for the explanation of some observations, for example, the mysterious outbreak in Amoy Gardens. Oftentimes, such models are explaining certain patterns, trends, or relationships (first types of models). Third, due to the predictive power of a model, it can often be subsequently applied, for example, the preventive measures in reducing the spreading of SARS are a product resulting from the transmission model of SARS.

It is also worth noting that many different levels of representations were evoked in the scientific research and the dissemination of findings. The phylogenetic tree and the diagram representing the transmission of the disease are symbolic. Yet the phylogenetic tree represents the evolution of SARS-like coronavirus which is at the submicro level; and the diagram representing disease transmission represents phenomena that are at the macro level. In the virus hunt, electron micrographs (at the submicro level) were useful for the identification of the likely causative virus (which needs further experiment based on Koch's postulates for confirmation). The fuller details of the coronavirus were obtained through genetic analysis (at the submicro level or more specifically the molecular level). The above examples may seem to suggest that contemporary scientific research does not make use of representations that are iconic. However, the pattern of spread in Amoy Gardens reveals that iconic diagrams at the macro level did play an essential role in modeling the way in which the disease was spread in the building. In different contexts and in fulfilling different needs, models at different levels of representations were evoked. In other words, scientific modeling is a purposeful activity and is conducted to fulfill the needs of particular contexts.

Modeling is unavoidably guided by the prior knowledge of and the preconceptual framework adopted by the researcher; for example, certain symptoms are more likely associated with certain family of viruses. In a way, while expert knowledge could help swiftly eliminate many possible unlikely causes through logic or evidence (e.g., sewage system rather than rodents is a more likely culprit for the infection pattern in Amoy Gardens), it would also inevitably lead to the possibility of missing a target or a breakthrough.

Construction of models could be prompted by curiosity or in fact is more often driven by social expectations and demands. When there is more than one model, the one with the greater descriptive/predictive/explanatory power will normally prevail.

\section{Models and Modeling Represented in Curriculum Guide}

To compare and contrast the models and modeling as represented in our newly reformed curriculum to those reflected in the authentic research as illustrated in several episodes of scientific inquiries in SARS, we conducted a simple content analysis of the Hong Kong Biology Curriculum and Assessment Guides (CDCHKEAA, 2007). We found 25 places where the document mentioned model(s)/ modeling, of which there was one instance that model referred to the behavior of 
teachers from whom their students should learn (p. 77). Such a use was not deemed relevant to our analysis. For the other 24 relevant places, we observed that there were three distinctive ways in which the idea of model/modeling was made use of in the document as described in the following sections. We then put forward our suggestion on how NOS could be better included in the new curriculum.

\section{Models as Physical Artifacts $(n=12$ places $)$}

Models are regarded as physical artifacts through which structures are observed (CDC-HKEAA, 2007). As teaching and learning activities, students were expected to "construct models of DNA and RNA" (p. 27), "examine models of the human brain, eye, ear and arm" (p. 36), and "examine prepared slides or models to identify features of mammalian skin that are related to body defence" (p. 42). That is, models are regarded as aids through which students learn target scientific ideas. In this connection, they are teaching models based on Gilbert's (2005) taxonomy of models.

The use of physical models extended from teaching and learning to school-based assessment (CDC-HKEAA, 2007). According to the document, teachers were recommended to use "a variety of assignment tasks - such as exercises, essays, designing posters or leaflets, and model construction. . .to allow students to demonstrate their understanding and creative ideas" (p. 97).

Models as physical artifacts were represented not only as the most frequently used models among the other models but were also most widely made use of in the classrooms. The curriculum was meant to be taught from grade 10 to grade 12 and was allocated $270 \mathrm{~h}$ for a complete coverage (p. 14). Teachers were expected to spend $200 \mathrm{~h}$ to cover the compulsory part that was composed of four topics, namely, cell and molecules of life, genetics and evolution, organism and environment, and health and diseases. It was observed that examining or building physical models were suggested for all of these topics. For example, they included building fluid mosaic model (p. 22) and DNA model (p. 27), and examining mammalian skin model (p. 42) and kidney model (p. 46).

\section{Models as Virtual Artifacts $(n=6$ places $)$}

Models were regarded as computer simulations through which physical phenomena could be represented, tested, and manipulated (CDC-HKEAA, 2007). In this regard, models were introduced in the context of using the Internet and technology in facilitating students' learning. The document suggested that "modeling software, which allows students to test their proposed models through virtual experiments, is useful in helping students to develop conceptual understanding. .." (p. 108).

Virtual experiments could have been applicable in different biological topics. Throughout the curriculum guide, however, there was only one single suggestion that such strategies were made use of. The Suggested Learning and Teaching 
Activities section of the topic Genetic and Evolution listed "Use computer simulations or other simulations to model natural selection" (p. 27). In another part of the document which advised teacher how to use information technology to exercise interactive teaching, the same statement was reiterated (p. 85). In short, although there were six suggestions when models could be used as virtual artifacts, their proposed use was very limited.

\section{Models as Exemplar Phenomena $(n=1$ place $)$}

Given the complexity of the physical world and biological organisms, scientists have to idealize or simplify the phenomena to be studied. For example, the complexity of inheritance of characteristics of organisms was simplified to the study of single features (hence Mendelian genetics). In school science, typically, it is the study of the flower color of the parent plants and their offspring. Atkins (2003) and Gilbert (2005), respectively, called such simplified but representative phenomena as "core phenomena" (p. 2) and "exemplar phenomena" (p. 10) regarding the study of the core/exemplar phenomena as a key part of scientific activities and scientific method.

Materials to be included in a curriculum inevitably would have to be selective. Given the myriad number of animals, their characteristics, and how they survive in their environment, human beings were chosen as the exemplar phenomena. The preamble to the topic Organism and Environment in CDC-HKEAA (2007) stated that "[s]tudents will study reproduction, growth and development to understand how organisms perpetuate and proliferate in the environment. The human being is used as a model for students to understand the essential life processes of animals" (p. 28).

In this topic, among other biological concepts, students were expected to study life processes of animals, which included nutrition, gaseous exchange, growth and reproduction, nervous and hormonal coordination, movement, and homeostasis. Based on these contents to be covered, it is unlikely that the selection of human beings as a model/exemplar phenomenon reflected the use of a simplified phenomenon (for human beings are highly complex and sophisticated). Other than the statement quoted above, the document did not elaborate on how human beings could be a model of animals, which include insects, fishes, birds, and so on. It is likely that the selection was (justifiably) based on the familiarity and relevance of human beings to students.

\section{Models as Processes/Outcomes of the Scientific Enterprise $(n=5$ places $)$}

Models were regarded as activities and as products of the scientific community (CDC-HKEAA, 2007). It could be found under the "curriculum emphases" section of the document that "[the curriculum] should enable students to...formulate and 
revise scientific explanations and models using logic and evidence" (p. 12). Elsewhere, a statement that "students should be able to... appreciate the uses and limitations of scientific models" (p. 19) was indicated.

Based on these two statements, it might seem that the curriculum adopted a model-based approach to science teaching and learning. Nevertheless, a scientific model was addressed in only one model: "Use the fluid mosaic model to explain the properties and functions of cell membrane" (p. 19). Also students were expected to "be aware that biological knowledge and theories are developed through observations, hypotheses, experimentations and analyses (e.g., fluid mosaic model of cell membrane structure)" (p. 18).

Without going to the detailed discussion on whether logic and evidence were the key to the formulation to a model, or scientific models were developed through observations, hypotheses, experimentations, and analyses, we argue that the inclusion of only a scientific model in the content specification was inconsistent with the overarching curriculum emphasis. This situation leaves a big challenge for teachers if they are to achieve the curriculum aims based on a single scientific model.

\section{Summary}

We observed that the curriculum made different uses of the idea of models. In general, models-be they physical or virtual-were taken to be teaching and learning aids through which the students would learn target biological concepts. Such a use of models was evident in the frequency of their use across different biological topics. Models as exemplar phenomena were also referred to in the curriculum. As argued above, due to the complexity of human beings, it is debatable whether humans can be regarded as a model of other animals.

The curriculum document (CDC-HKEAA, 2007) was written in line with the advocacy of the science education literature. Nature and history of biology was taken to be one of the three curriculum emphases. We have argued elsewhere that the focus on NOS might be more of paying lip service than of having substantial commitment (Wong, Yung, \& Cheng, 2010). An issue which further confounds the problem was that scientific models/modeling as outcomes and processes of the scientific enterprise were underrepresented and were used interchangeably with teaching and learning aids.

We argue that the use of models as physical and virtual artifacts has been a daily practice of biology teachers; how they are to be used have been widely discussed in the existing literature. In contrast, how teachers could help students learn the notion of modeling and models - as a process and outcomes of scientific activities (rather than simply as artifacts or copies of reality) while covering curriculum contents that would be assessed in high-stake public examination-remains a challenge for biology teachers and science educational researchers. However, we believe that the in-depth analysis of the four scientific inquiries during the SARS crisis has provided convincing evidence that modeling and scientific models could be vividly 
illustrated by appropriate episodes in the authentic scientific inquiries in SARS as other aspects of NOS reported earlier (Wong et al., 2009). If a similar effort is put into developing instructional materials with a focus on promoting the understanding of modeling/models/multiple levels of representations as we did for the other aspects of NOS (Wong et al., 2008), we anticipate that similar favorable learning outcomes could be achieved.

\section{Concluding Remarks}

This chapter discusses how scientific models at different levels, namely, the macro, the submicro, and the symbolic, were developed in the SARS-related scientific research. The discussion serves to exemplify the roles of scientific models and modeling in knowledge construction and representations in biological sciences. In the authentic practice, scientific models are developed to describe, explain, and predict physical phenomena. In solving different problems, scientific models of different levels are made use of in ways that were fit for their purposes.

Compared with the authentic scientific practice, we argue, based on our observation of a school biology curriculum, that the scope of models advocated in school biology was rather limited. Also, the roles of models as teaching tools and as outcomes/process of scientific research are not differentiated. There might be an issue that such an unspecific use of models would affect the quality of teaching and learning of school science/biology. We suggest that a way forward for research is to further investigate how biology teachers handle scientific models (rather than merely teaching models) in their classrooms and to study students' learning of scientific models. Meanwhile, as far as curriculum material development is concerned, we support the view of van Dijk (2011) that exemplars based on authentic and contemporary scientific practice could be further developed and the SARS crisis could again be turned into opportunity as an excellent local exemplar for a rich discussion and illustration of the nature and roles of scientific models and modeling as part of NOS.

\section{References}

Abd-El-Khalick, F., \& Lederman, N. G. (2000). Improving science teachers' conceptions of the nature of science: A critical review of the literature. International Journal of Science Education, 22, 665-701.

Abraham, T. (2004). Twenty-first century plague: The story of SARS. Hong Kong: Hong Kong University Press.

American Association for the Advancement of Science. (1993). Benchmarks for scientific literacy. New York: Oxford University Press.

Atkins, P. (2003). Galileo's finger: The ten great ideas of science. Oxford: Oxford University Press. 
Bell, R., Blari, L., Crawford, B., \& Lederman, N. (2003). Just do it? Impact of a science apprenticeship program on high school students' understandings of the nature of science and scientific inquiry. Journal of Research in Science Teaching, 40(5), 487-509.

CDC-HKEAA. (2007). Physics/chemistry/biology/integrated science curriculum guide and assessment guide (secondary 4-6). Hong Kong: Curriculum Development Council and Hong Kong Examinations and Assessment Authority.

Centers for Disease Control and Prevention, Atlanta. (2003). Update: Outbreak of Severe Acute Respiratory Syndrome - Worldwide, 2003. Morbidity and Mortality Weekly Report, 52(12), 241-248.

Cheng, M. M. W., Wong, S. L., \& Yung, B. H. W. (2007, April). Students' understanding of scientific models in different contexts: The impact of teaching on the nature of models. Paper presented at the National Association for Research in Science Teaching (NARST) annual meeting. New Orleans, LA.

Council of Ministers of Education. (1997). Common framework of science learning outcomes. Toronto, ON, Canada: CMEC Secretariat.

Department of Health, Government of Hong Kong Special Administration Region. (2003). Outbreak of severe acute respiratory syndrome (SARS) at Amoy Gardens, Kowloon Bay, Hong Kong: Main findings of the investigation. Retrieved November 18, 2011, from http:// www.info.gov.hk/info/ap/pdf/amoy_e.pdf

Gilbert, J. K. (2005). Visualization: A metacognitive skill in science and science education. In J. K. Gilbert (Ed.), Visualization in science education (pp. 9-27). Dordrecht, the Netherlands: Springer.

Gilbert, J. K., \& Treagust, D. (2009). Macro, submicro and symbolic representations and the relationship between them. In J. K. Gilbert \& D. Treagust (Eds.), Multiple representations in chemical education (pp. 1-8). Dordrecht, the Netherlands: Springer.

Khishfe, R., \& Abd-El-Khalick, F. (2002). The influence of explicit/reflective versus implicit inquiry-oriented instruction on sixth graders' views of nature of science. Journal of Research in Science Teaching, 39, 551-578.

Kwan, J. (2011). Interactive relationships among teachers' intentions, beliefs, pedagogical content knowledge and classroom instruction on the nature of science. Unpublished $\mathrm{PhD}$ dissertation, The University of Hong Kong, Hong Kong.

Lederman, N. G. (1992). Students' and teachers' conceptions of the nature of science: A review of the research. Journal of Research in Science Teaching, 29, 331-359.

Li, W., Shi, Z., Yu, M., Ren, W., Smith, C., Epstein, J. H., et al. (2005). Bats are natural reservoirs of SARS-like coronaviruses. Science, 310(Science), 676-679.

Millar, R., \& Osborne, J. (Eds.). (1998). Beyond 2000: Science education for the future. London: King's College.

Samarapungavan, A., Westby, E., \& Bodner, G. (2006). Contextual epistemic development in science: A comparison of chemistry students and research chemists. Science Education, 90(3), 468-495.

Schwartz, R. S., Lederman, N. G., \& Crawford, B. (2004). Developing views of nature of science in an authentic context: An explicit approach to bridging the gap between nature of science and scientific inquiry. Science Education, 88(4), 610-645.

Tao, P. K. (2002). A study of students' focal awareness when studying science stories designed for fostering understanding of the nature of science. Research in Science Education, 32, 97-120.

van Dijk, E. M. (2011). Portraying real science in science communication. Science Education, 95 (6), 1086-1100.

Wong, S. L., Hodson, D., Kwan, J., \& Yung, B. H. W. (2008). Turning crisis into opportunity: Enhancing student teachers' understanding of the nature of science and scientific inquiry through a case study of the scientific research in Severe Acute Respiratory Syndrome. International Journal of Science Education, 30, 1417-1439. 
Wong, S. L., Kwan, J., Hodson, D., \& Yung, B. H. W. (2009). Turning crisis into opportunity: Nature of science and scientific inquiry as illustrated in the scientific research on Severe Acute Respiratory Syndrome. Science Education, 18, 95-118.

Wong, S. L., Yung, B. H. W., \& Cheng, M. W. (2010). A blow to a decade of effort on promoting teaching of nature of science. In Y.J. Lee (Ed.), The world of science education: Handbook of research in science education research in Asia (pp. 259-276). Rotterdam, the Netherlands: Sense.

Wong, S. L., Wan, Z., \& Cheng, M. M. W. (2011). Learning nature of science through socioscientific issues. In T. D. Sadler (Ed.), Socio-scientific issues in the classroom: Teaching, learning and research (pp. 245-269). Dordrecht, the Netherlands: Springer. 